and D. George (eds.)

\title{
Pleijelius longae n. gen., n. sp., a remarkable deep water polychaete from the Northwestern Atlantic (Polychaeta: Hesionidae)
}

\author{
S.I. SALAZAR-VALLEJO ${ }^{1}$ and J.M. (LOBO) ORENSANZ ${ }^{2}$ \\ ${ }^{1}$ Depto. Ecología Acuática, ECOSUR, Apdo. Postal 424, Chetumal, Q. Roo, 77000 México \\ E-mail: salazar@ecosur-qroo.mx) \\ ${ }^{2}$ Centro Nacional Patagónico, Puerto Madryn, Chubut, Argentina
}

\begin{abstract}
SUMMARY: A new genus and species, Pleijelius longae n. gen., n. sp., is proposed for a small hesionid from deep water off Woods Hole, in the Northwestern Atlantic Ocean. The new genus can be separated from other members of the family by having six pairs of enlarged anterior cirri, abundant dorsally-oriented notochaetae, provided with a single row of 2-4 denticles, and 10 cushion-shaped marginal pharynx papillae. A cladistic analysis indicates that this new taxon falls within Hesionidae and is the sister group to Hesioninae. A key to all 'hesionid' genera is also included.
\end{abstract}

Keywords: taxonomy, deep-water, key.

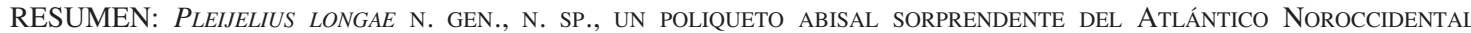
(PolyChAETA: HesionidAe). - Un nuevo género y especie, Pleijelius longae n. gen., n. sp., es propuesto para un pequeño hesiónido sorprendente abisal recogido frente a Woods Hole, en el Atlántico Noroccidental. El nuevo género puede separarse de los otros de la familia por contar con seis pares de cirros anteriores alargados, notochaetas abundantes dirigidas dorsalmente, provistas con una hilera de 2-4 dentículos, y faringe con 10 papilas redondeadas marginales. Un análsis cladístico indica que el nuevo género pertenece a Hesionidae y es el grupo hermano de los Hesioninae. También se presenta una clave para todos los géneros de "hesiónidos" del mundo.

Palabras clave: taxonomía, abisal, clave.

\section{INTRODUCTION}

Hesionids have been reviewed extensively and in detail by Pleijel (1998); members of the family have cylindrical bodies and cephalisation of the anterior end (Wilson, 2000); they have a variable number of enlarged anterior cirri, and lateral parapodia with notopodia variously developed, provided with simple chaetae, while neuropodia are better developed and provided with compound chaetae. The family includes about 20 genera which are separated using the number of anterior enlarged cirri, the presence and type of palps, the presence and position of a median antenna, the development of nuchal organs, the notopodia and chaetae, the presence of jaws and marginal papillae in the pharynx, and the presence of penises.

Here we propose a new hesionid genus characterized by an unusual combination of features, which place it clearly apart from any other known hesionid genera. During a revision of small chrysopetalids from all over the world, one of us (JMO) found several individuals previously identified as such, that do not fit into the family even after the expanded new arrangement that would contain four new genera (Petersen et al. ms). It should be 
stressed that this is just a superficial resemblance, but they are not chrysopetalids.

\section{MATERIALS AND METHODS}

The holotype has been observed with light microscopy (LM) and its morphology was used for the description. The illustrations are photographs of the holotype with LM and of SEM of non-type specimens. Three non-type specimens were cross-sectioned to study parapodial structures, pygidium and pharynx papillae with LM, and two other specimens were gold-coated for SEM. An anterior fragment was longitudinally sectioned to observe the internal structure of the pharynx and to ascertain if it has any jaws.

A cladistic analysis was attempted in order to define its relationships with the hesionids. Thus, it was scored for all characters and added into the matrix compiled by Pleijel and Rouse (2000, Tables 1-2) resulting in a 42 taxa and 97 characters matrix. Following their same settings, since they have made the only cladistic delineation for the group (and not necessarily by endorsing their codification method or character evaluation), all characters were coded binary absent/present and parsimony analysis and character state reconstruction were performed with MacClade 4.05 (Maddison and Maddison, 2001), and PAUP 4.0 (Swofford, 1998). After Pleijel and Rouse (2000), heuristic tree searches were executed with PAUP's default settings, except for taxon addition sequence which was set to random with 100 replicates, initial seed 1. Autapomorphies were included during the analysis, but are excluded from reported consistency indices (CI). Character list and data matrix are available in: w2.ecosurqroo.mx/bentos/cladistics/SV\&Oz. This analysis was run changing outgroups, and in one option, the new taxon was regarded as the outgroup. Because of the contrasting results of this analysis compared with the previous one, a traditional discussion is inserted before the one on cladistics.

Considering that a general key to all hesionid genera has not been published since Fauchald (1977), we thought it appropriate to construct one that includes recently described taxa and, at the same time, follows Pleijel (1998). However, it includes some genera that do not belong in the Hesionidae, but since they have been associated with them in the past, they were inserted to make it as comprehensive as possible.

\section{SYSTEMATICS}

Class POLYCHAETA Grube, 1850

Order Phyllodocida Dales, 1962

Suborder NEREIDIFORMIA Glasby, 1993

Superfamily NEREIDOIDEA Johnston, 1845

Family Hesionidae Grube, 1850

Pleijelius n. gen.

Diagnosis. Hesionids with 10 cushion-shaped pharynx papillae; enlarged elongated ventral cirri on segments 1-3; enlarged elongated dorsal cirri on segments 1-4; no notochaetae in segments 1-3; no neurochaetae in segments 1-3.

Apomorphy based definition. Hesionid with pharynx provided with 10 marginal papillae, all cushion-shaped.

\section{Type species. Pleijelius longae n. sp.}

Discussion. Pleijelius n. gen. is an unequivocal member of Hesionidae because of the presence of enlarged dorsal cirri in segment 3 and of its cephalisation. Paraphrasing Pleijel and Rouse (2000:166): no other polychaete group has Hesionid apomorphies like elongated dorsal and ventral cirri as well as reduced parapodial lobes and chaetae on segments 1-3.

In a traditional approach, it resembles Ophiodrominae Pleijel, 1998, but following the key below, it seems to be closest to 'Capricornia' Pleijel and Rouse, 2000. This has been regarded as a member of Gyptini Pleijel, 1998, which is defined by, among other features, large ventral penises on segment 9 (chaetiger 6), two types of notochaetae (one with double rows of denticles), and pharynx with triangular ciliated papillae. Pleijelius n. gen. differs from 'Capricornia' by lacking external genital organs, by having a single type of notochaetae ( $\sin$ gle row of distal denticles), and pharynx with rounded smooth papillae.

Pleijelius n. gen. could belong in Ophiodrominae Pleijel, and its tribal placement in Gyptini Pleijel is even more doubtful. The tribe Gyptini is diagnosed by being ophiodrominidwith dorsally inserted antenna and by including notopodial capillaries with two rows of teeth. Pleijelius n. gen. differs from all members in the group by having all notochaetae as smooth capillaries with distal denticles, but with 
teeth arranged in a single row, not two rows as in other genera; this difference is regarded as a secondary reduction. The tribe has recently received a new genus (Pleijel, 2001), another group described as a LITU (Pleijel and Rouse, 2000), and it might include other recently described genera (Westheide, 2000). Thus the tribe could include Amphiduros Hartman, 1959, Amphiduropsis Pleijel, 2001, 'Capricornia' Pleijel and Rouse, 2000, Gyptis Marion and Bobretzky in Marion, 1874, Hesiodeira Blake and Hilbig, 1990, Lizardia Pleijel and Rouse, 2005, and Parahesione Pettibone, 1956 (possibly Mahesia Westheide, 2000, which has an anterior median antenna). 'Capricornia' and Lizardia differ from all other members in the tribe by the presence of long penises in segment 9 in the former, and in posterior chaetigers or in the anal plate in the latter, and Parahesione is unique in lacking a median antenna. Pleijelius n. gen. and Hesiodeira differ from Amphiduros, Amphiduropsis and Gyptis by lacking alternating short and long dorsal cirri. The main difference between Pleijelius n. gen. and Hesiodeira is in the number of enlarged anterior cirri, numbering 6 pairs in the former and 8 pairs in the latter, and the presence of abundant dorsal notochaetae in expanding bundles, especially in anterior chaetigers, giving it a rough resemblance to Dysponetus Levinsen, 1879 (Chrysopetalidae), Notopygos Grube, 1855 or Linopherus de Quatrefages, 1865 (Amphinomidae). The general resemblance is caused by the enlarged anterior chaetigers and the dorsally directed notochaetae, but it is only just a superficial similarity.

Regarding the pharynx papillae, after Pleijel (1998), there are at least seven genera provided with 10 distal papillae (Gyptis, Heteropodarke Hartmann-Schröder, 1962, Nereimyra de Blainville, 1828, Ophiodromus Sars, 1862, Podarkeopsis Laubier, 1961, Sirsoe Pleijel, 1998, and Syllidea de Quatrefages, 1866), but none of them has cushionshaped papillae, including the other Gyptini. To date the only two genera to be provided with that type of papillae are Leocrates Kinberg, 1866, and Leocratides Ehlers, 1908, but since they both have 8 pairs of enlarged anterior cirri, they are not so closely related to Pleijelius.

It might not seem relevant, but to avoid any potential confusion, some facts about the relationships between chrysopetalids and hesionids are included. These two families are so different in appearance that they have been regarded as inde- pendent groups by most authors. Chrysopetalids have been set apart by the presence of notopodial fans of chambered paleae, which sometimes can be replaced solely by chambered spines (WatsonRussell, 2000). The general affinities between the two families were summarized by Perkins (1985): single pair of bilateral jaws, simple notochaetae and compound neurochaetae, similar number of antennae and palps, and aciculae in cirrophores of segment 1. Glasby (1993) first investigated the cladistic relationships of Chrysopetalidae and Hesionidae with other nereidoids; he found a hesionid-chrysopetalid sister group relationship. Further, Dahlgren and Pleijel (1995) performed a cladistic analysis to find out the affinities between these two groups, and included Aphroditidae, Polynoidae and Hesionidae as outgroups. Among other characters, they considered three features of notochaetae (paleae, transverse and longitudinal striae). In 8 out of 10 trees, hesionids could not be separated from chrysopetalids; they concluded that their delineation required further investigation. In a subsequent study (Pleijel and Dahlgren, 1998) they included more characters and more families, but instead of using the three characters so obviously associated with chrysopetalids, and presumably in an attempt to reduce any potential bias, they included chambered chaetae instead. The result was that chrysopetalids and hesionids seemed to be both monophyletic and non-overlapping. Later, combining molecular and morphological data, Dahlgren et al. (2000) concluded that chrysopetalids and hesionids are non-overlapping and that nereidids, not hesionids, are the sister group of chrysopetalids. Pleijelius n.gen. has a general resemblance to species in Dysponetus Levinsen, 1879 , or to some amphinomids, but they differ by the number of enlarged anterior cirri and the type of notochaetae.

Cladistics. The analysis produced 11 equally parsimonious trees (285 steps long, CI 0.34, RI 0.70 ), with topologies mostly contrasting with the ones found by Pleijel (1998), and Pleijel and Rouse (2000; 262 steps long, CI 0.34, RI 0.73). Thus, in the one nereidid + two chrysopetalids outgroup, in all trees:

'Capricornia' is the sister group to all hesionids, its affinities with Amphiduros are not confirmed in any of the trees. Some of this instability has been already stated (Pleijel and Rouse, 2000). 


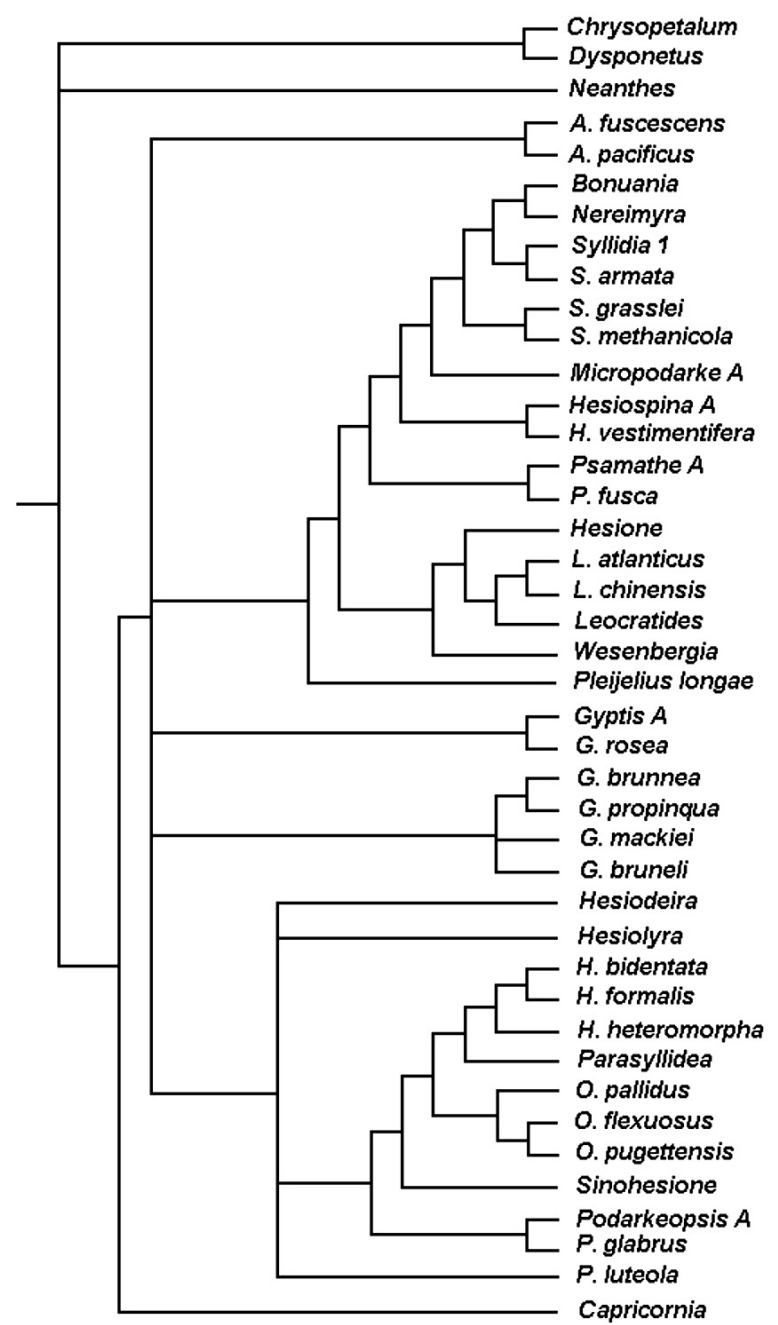

FIG. 1. - Strict consensus tree based on 11 equally parsimonious trees with taxon names simplified.

Hesiolyra Blake, 1985, which was recognized as an independent subfamily, collapses. Further, in two out of 11 trees it appears close to Hesiodeira, or as a sister group to Hesiodeira-Parahesione, in five other trees it is the sister group to Ophiodromini Pleijel, and in the others it falls within Ophiodromini having Parahesione as the sister group.

Pleijelius longae n. gen., n. sp., is the sister group for Hesioninae Grube, 1850; it can be distinguished by having 10 marginal papillae in the pharynx and each papillae cushion-shaped (characters 34 and 37, both $0-1$ ).

The strict consensus tree shows most of these features (Fig. 1) but most branches stem from a large polytomy, without 'Capricornia' and thus as a better resolved clade. The combinations of the outgroups and even the use of Pleijelius n. gen. as such, produced no significant change at all. However, these results are preliminary and the new topologies should be regarded as temporary pending the inclusion of more taxa or more characters (Pleijel 2003 pers. com.).

Etymology. This genus is named after Dr Fredrik Pleijel for his many, fine publications on taxonomy of polychaetes in general, especially on the taxonomy of the Hesionidae (without such publications this paper would hardly be possible), and because of his generous support to polychaete students from Latin America.

\section{Pleijelius longae n. sp.}

(Figs. 2-5)

Type material. Norhwestern Atlantic Ocean. Holotype is a complete specimen (USNM 68725), 14 additional paratypes (USNM 1020004), and two gold-coated specimens (ECOSUR), all collected from panel N37, $304 \mathrm{~km}$ off Woods Hole, Mass. (38 $18.4^{\prime} \mathrm{N}$, $\left.69^{\circ} 36.5^{\prime} \mathrm{W}\right), 3,500 \mathrm{~m}$ depth, R.D. Turner coll., Alvin dive 601, 5 Sep. 1975 (Id. C.D. Long as Dysponetus cf. bidentatus Day, 1954). Further data on later studies on deep sea wood panels are included elsewhere (Watson-Russell, 1991).

Description. Holotype (USNM 68725) complete (Fig. 2A), $3.6 \mathrm{~mm}$ long, $1.0 \mathrm{~mm}$ wide, with $26 \mathrm{seg}$ ments, 23 chaetigers. Body pale, with pigmented dorsal cirri; chaetigers 4-9 swollen, larger than previous or posterior ones. Notochaetae in dorsal expanding bundles, slightly deteriorated, with some anterior parapodia swollen, distorted, wider in middle segments.

Prostomium short, ovoid, broader than long, anteriorly straight, lateral and posterior margins fused to seg-
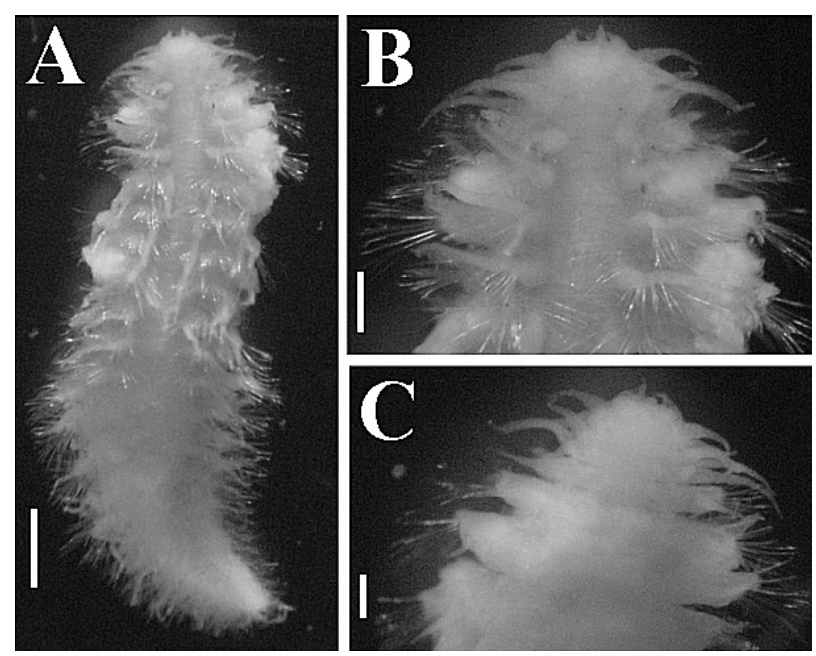

FIG. 2.-Pleijelius longae n. gen., n. sp., Holotype (USNM-68725), A. Dorsal view of the whole body, B. Anterior end in dorsal view, C. Anterior end in ventral view (scales.-A: $0.3 \mathrm{~mm}, \mathrm{~B}-\mathrm{C}: 0.1 \mathrm{~mm}$ ) 

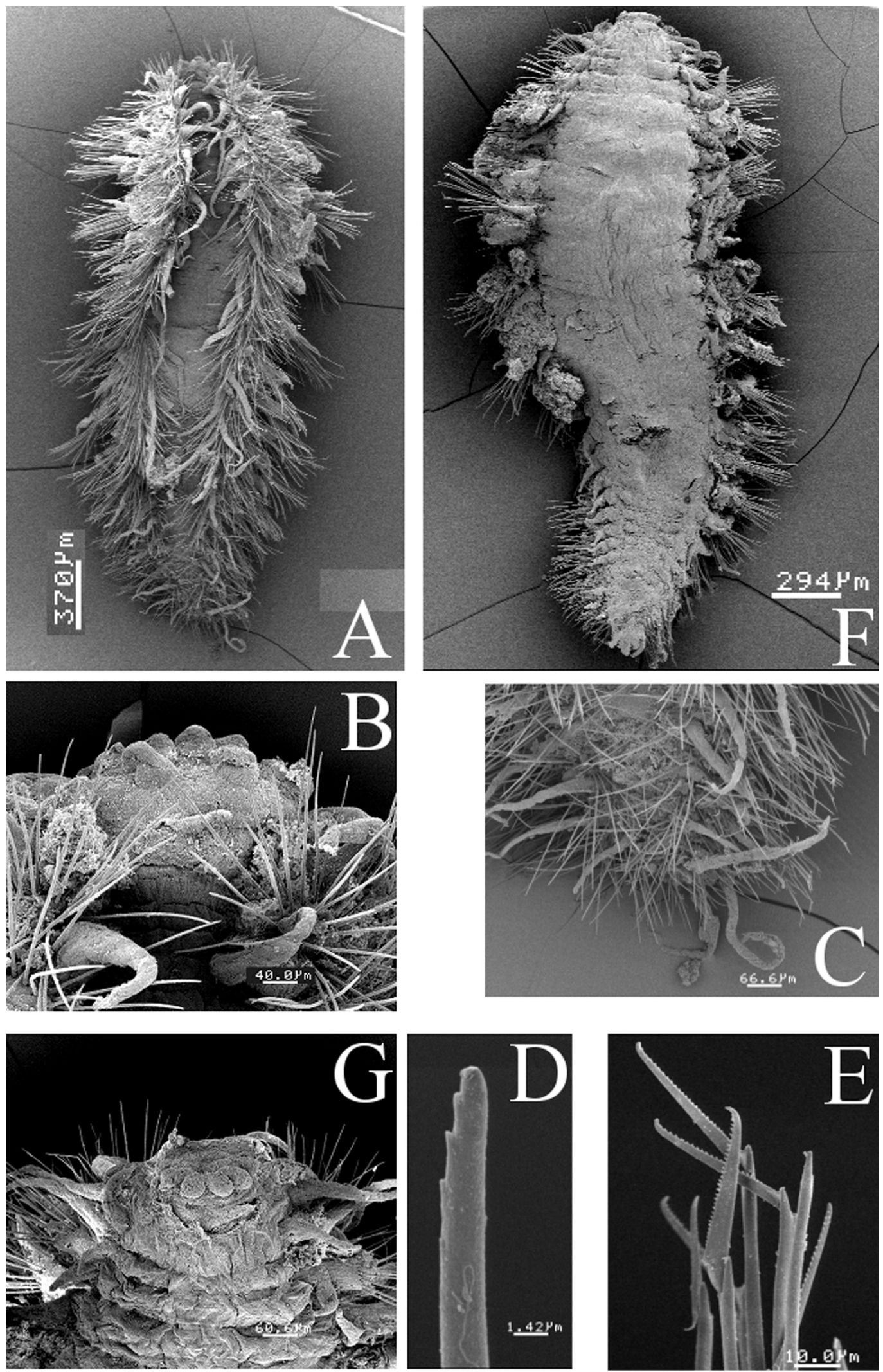

FIG. 3. - Pleijelius longae n. gen., n. sp., gold-coated non-type specimens (ECOSUR-P-01), A. Complete, dorsal view, B. Same, prostomium, dorsal view, showing the anterior appendices, pharynx slightly everted, C. Same, posterior end, dorsal view, note the long anal cirri, D. Same, tip of notochaeta showing distal tiny denticles, E.Same, neurochaetae, F. Another specimen, complete, ventral view, G. Same, anterior end in ventral view, showing pharynx everted and cushion-shaped papillae. 

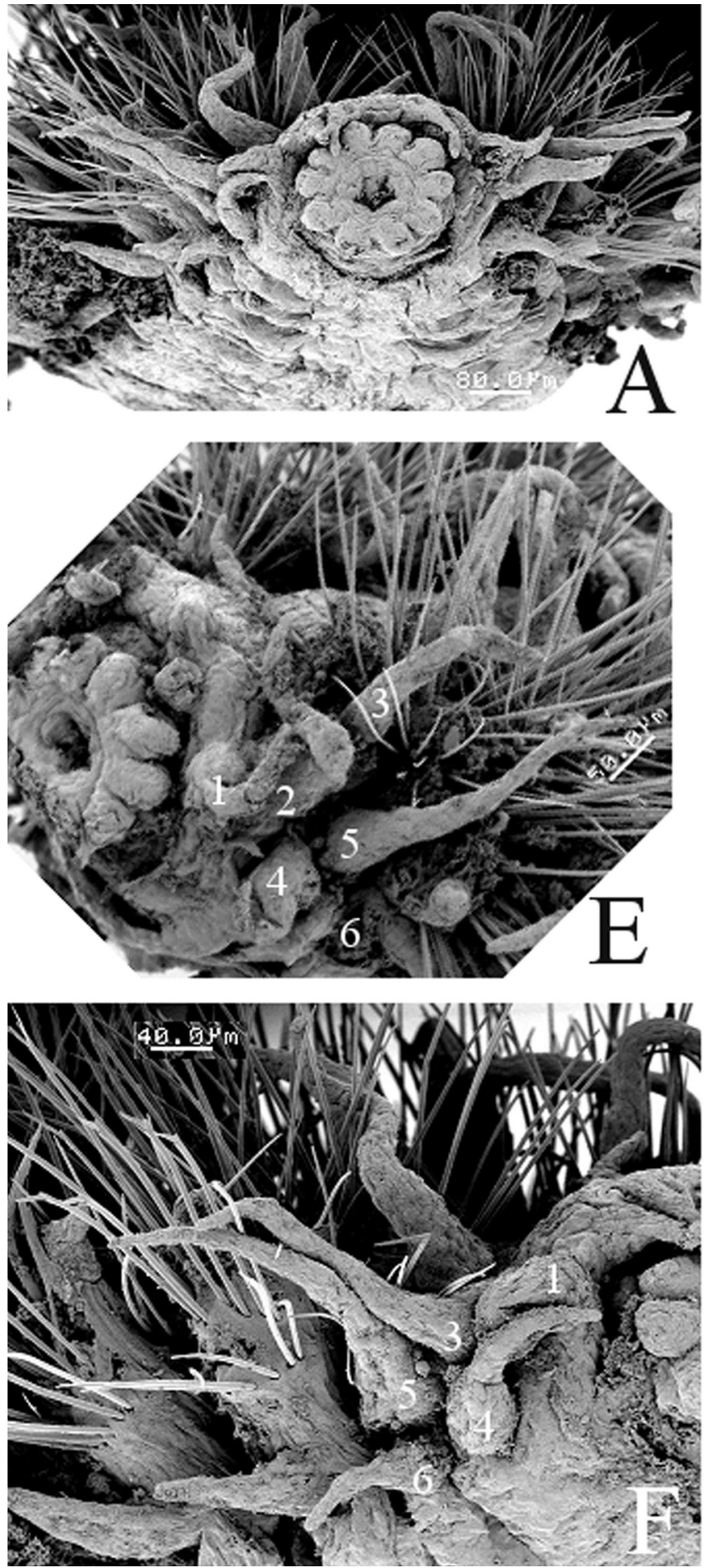
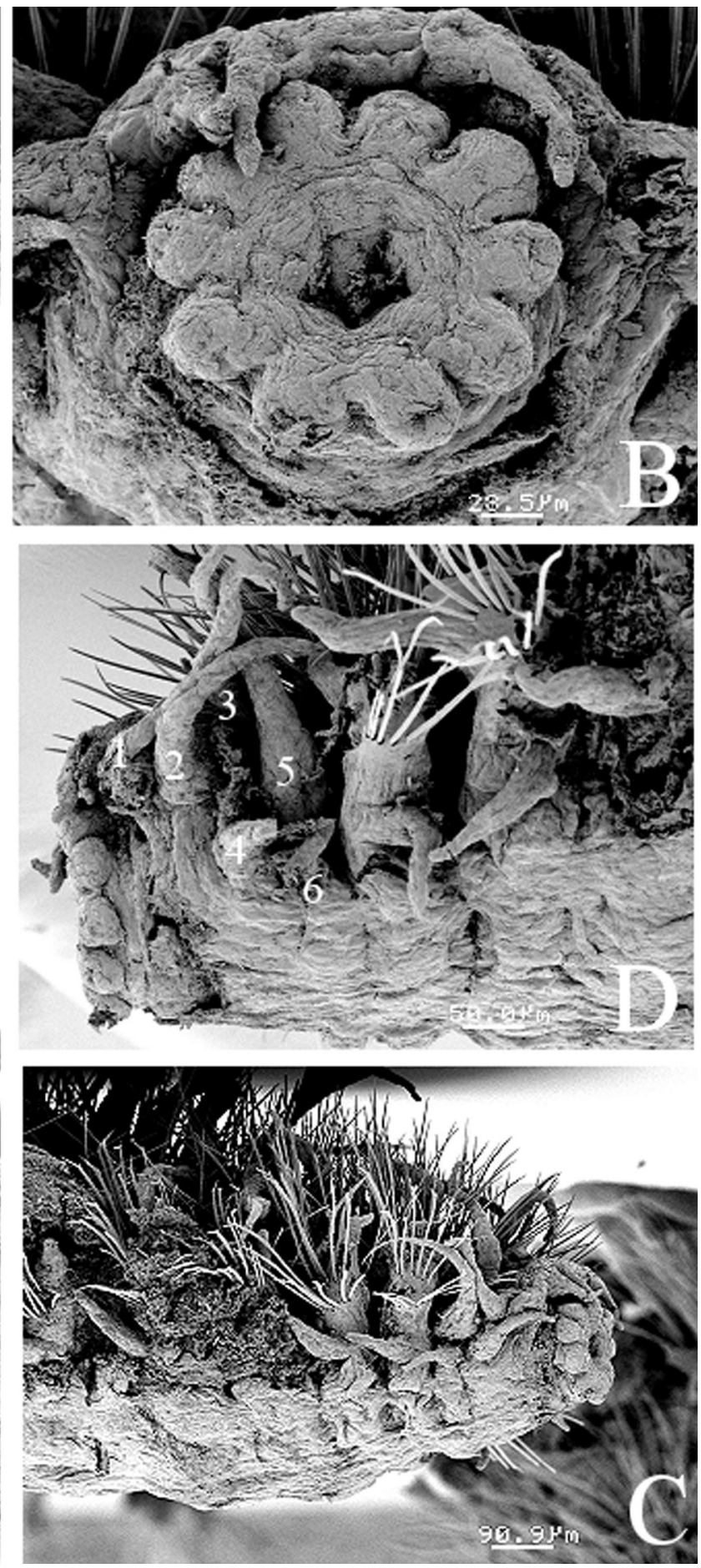

FIG. 4. - Pleijelius longae n. gen., n. sp., gold-coated non type specimens (ECOSUR-P-01), A. Anterior end in frontal view, B. Same, closeup to show smooth papillae, C. Same, anterior end in right side view, D. Same, anterior end in left side view, numbers refer to cirri, E. Same, left side-oblique view, F. Same, right side view.

ments 1 and 2. Without a facial tubercle. Lateral antennae and palps inserted on anterior margin, all short, about same size, acuminate (Figs. 2B, C, 3B); antennae cirriform, palps biarticulate, with palpophore thicker and shorter than palpostyle, directed anteroventrally. Median antenna arising from middle of prostomium
(Fig. 3B), shorter than lateral antennae; all antennae irregularly wrinkled. No eyes or corneas were observed. Nuchal organs widely separated dorsally, placed in the posterolateral corners of the prostomium.

Six pairs of enlarged anterior cirri in segments 13 (2:2:2); all cirriform, without distinct cirrophore 
(Fig. 4D-F). Cirri from segment 1 of about the same size; dorsal cirri longer than ventral cirri in the following two segments (Fig. 4E-F). First two pairs lateral to prostomium; last pair posterolateral, slightly more dorsal than preceding ones (Figs. 2B, 3B, 4DF). No chaetae or aciculae could be detected in segments 1-3.

Parapodia projected dorsolaterally over the anterior portion, each one half as long as body width (Fig. 5A,B). All parapodia from segment 4 biramous, apparently much contracted upon fixation. Each parapodium with a long, articulated dorsal cirrus, 3-4 times longer than ventral cirrus (Fig. 5B). Notopodia with long, slightly pigmented dorsal cirri, may surpass neuropodial lobe. Dorsal cirri about same size throughout body, not alternating in size but slightly alternate in position (Fig. 3A). Each dorsal cirrus cirriform, non-dehiscent, stemming from a pigmented base; each cirrus surrounded by abundant notochaetae, all notochaetae smooth capillaries, with a single row of 2-4 tiny distal denticles (Figs. 3D, 5C), 20-24 per fascicle.

Neuropodia elongated, with long acicular lobes; neuroaciculae distally curved. Neurochaetae long heterogomph falcigers, 14-16 per fascicle, some directed upwards, others laterally, of variable length, becoming smoother in posterior chaetigers (Fig. 3E); handle finely chambered, blade denticulate, unidentate (Fig. 5D). Ventral cirri cirriform (lost in many chaetigers), longer than neuropodial lobe. Aciculae yellow, long, acuminate; in some parapodia curved back upon themselves, possibly indicating a strong parapodial contraction.

Pygidium almost completely obscured by chaetae; with two pairs of cirriform anal cirri (Fig. 3C), as long as the last three chaetigers; one pair dorsal, other lateroventral. Dorsal pair directed posteriorly, making it difficult to separate each cirrus alignment.

Ventral body surface smooth (Figs. 2C, 3F, 4CD); when observed with transmitted light from the ventral side, the body shows some denser regions in each chaetiger with lighter areas along the midventral line and over septa (Fig. 2B,C). Mouth with ventral lobes (lip glands) (Fig. 4E). Pharynx everted, short, with 10 marginal rounded, smooth papillae (Figs. 3G, 4A-C, E), without jaws.

Paratypes 2.5-3.2 mm long (mean $=2.95), 0.8$ $1.2 \mathrm{~mm}$ wide $($ mean $=1.04)$, with $21-28$ chaetigers $($ mean $=24.6)$, all damaged; most anteriorly swollen, chaetigers 1-3 not as expanded as

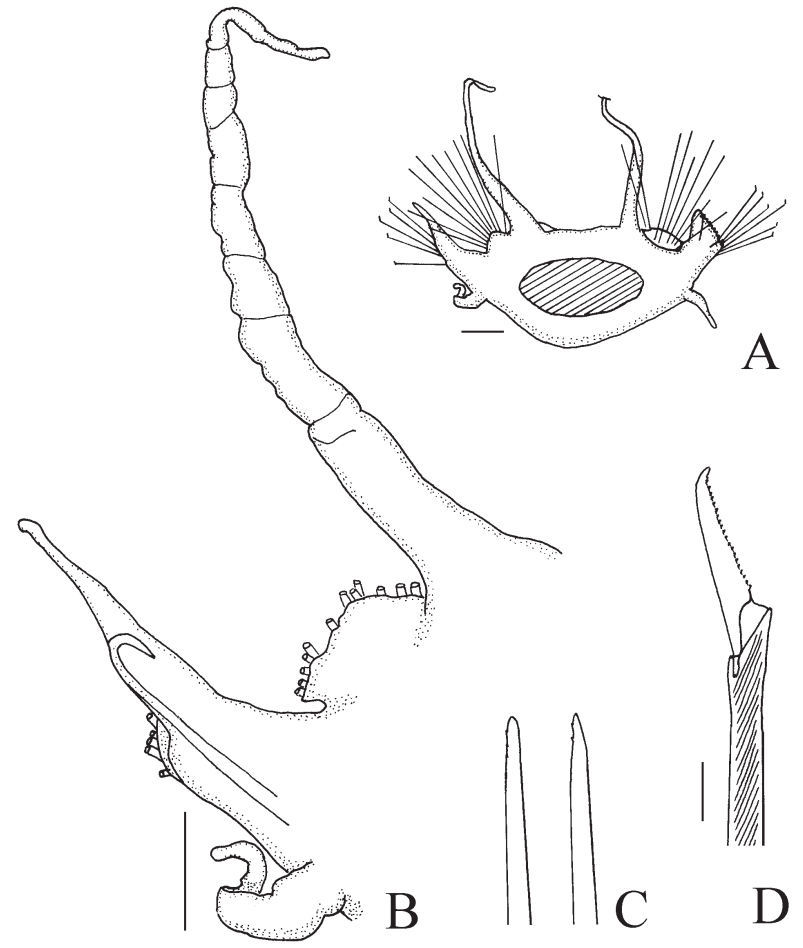

FIG. 5. - Pleijelius longae n. gen., n. sp., non-type fragment. A. Schematic cross-section of anterior chaetiger, B. Same, enlarged to show curved acicula (schematic), C. Same, tips of two notochaetae, D. Same, tip of neurochaetae (Scales.-A: $80 \mathrm{~mm}, \mathrm{~B}: 230 \mathrm{~mm}, \mathrm{C}-$ D: $11 \mathrm{~mm})$.

chaetigers 4-9; most with a thick layer of adherent foreign particles over the parapodia, making observation difficult. No gametes were observed.

Etymology. The species is named after Charlene D. Long, who has been engaged in ecological studies including polychaetes, for her work on Bahamian polychaetes, and because she noticed the peculiar morphology of these hesionids, which she regarded as a Dysponetus-looking undescribed species.

Type locality. Off Woods Hole, Massachusetts, United States, Northwestern Atlantic Ocean.

Discussion. There are several hesionids described from deep water (Pettibone, 1970; Hartman, 1971; Hartmann-Schröder, 1977, 1982; Kirkegaard, 1995); however, so far, there has been no hesionid species from either deepwater or shallow water, that has dorsally-directed notochaetae provided with a single row of distal denticles, rendering a remarkable morphology within the family. As stated by Pleijel and Rouse (2000:167), Pleijelius n. gen. exhibits in its adult stage some hes- 
ionid larval features like small size, 10 pharynx papillae, and first chaetae from chaetiger 4. Like Pleijel and Rouse we cannot determine whether these features are plesiomorphic or paedomorphic characters.

\section{Key to the genera of the 'Hesionidae'}

The genera that lie outside the family have been marked with an asterisk. Authors and years have been included for completeness. While counting anterior enlarged cirri, the count should include those that are paired; i.e., dorsal and ventral cirri arising from the same achaetous segment.

1 With eight pairs of enlarged anterior cirri ...2

- With six pairs of enlarged anterior cirri . . . 14

- With four pairs of enlarged anterior cirri . . 26 26

2(1) Body stout with less than 20 chaetigers .... 3

- Body variable, often with more than 20 chaetigers $\ldots \ldots \ldots \ldots \ldots \ldots \ldots \ldots$

3(2) Palps biarticulated, palpophore well developed ........................4

- Palps simple .... Wesenbergia Hartman, 1955

- Palps absent ........ Hesione Lamarck, 1818

4(3) Parapodia biramous, notosetae present ..... . .............. Leocrates Kinberg, 1866

- Parapodia uniramous (notosetae absent) ..... ...............Leocratides Ehlers, 1908

5(2) Palpophore well developed (palps biarticulated) $\ldots \ldots \ldots \ldots \ldots \ldots \ldots$

- Palpophore reduced (palps 'simple'); parapodia biramous .................... 12

6(5) Parapodia with capillary notosetae . . . . . . 7

- Parapodia without notosetae, with small hooks . ..... Hesiospina Imajima and Hartman, 1964

7(6) Median antenna anterior . . . . . . . . . . 8 8

- Median antenna central; without facial tubercle; nuchal organs dorsally coalescent . . . . . . . . .... . . . . . . Amphiduros Hartman, 1959

- Without median antenna ... . . . . . . . . . 10

8(7) With lip glands; nuchal organs dorsally coalescent .... Gyptis Marion and Bobretzky in Marion, 1874

- Without lip glands .................9

9(8) Notopodia with two cirriform branchial filaments; notochaetae large, abundant ....... ...... Branchiohesione Ruta and Pleijel, 2006

- Notopodia without branchial filaments; notochae tae sparse, short .. Podarkeopsis Laubier, 1961 10(7) Nuchal organs dorsally separated; pharynx without jaws and 10 marginal papillae ...... ................. Sirsoe Pleijel, 1998

- Nuchal organs coalescent ............ 11

11(10) Pharynx margin papillated . . . . . . . . . . ............. Psamathe Johnston, 1836

- Pharynx margin smooth ........... . Dalhousiella McIntosh, 1901

12(5) Prostomium rectangular; median antenna anterior; external genital organs present or absent ...................... 13

- Prostomium ovoid; median antenna central; males without external genital organs ....... ............ Amphiduropsis Pleijel, 2001

13(12) Dorsal cirri articulated; anal cirri feebly articulated; males with penises in chaetiger 10; pharynx with some 10 marginal papillae ...... ......... Sinohesione Westheide, Purschke and Mangerich, 1994

- Dorsal cirri smooth; anal cirri clearly articulated; no external genital organs; pharynx distally smooth .......... Mahesia Westheide, 2000 14(1) Prostomium with three antennae ..... 15 - Prostomium with two antennae ......... 21 15(14) Palpohore well developed (palps biarticulated) ......................... 16

- Palpophore reduced (palps 'simple') . . . . 18 16(15) Median antenna anterior; without lip glands . Ophiodromus Sars, 1862

- Median antenna central . . . . . . . . . . . 17

17(16) With facial tubercle; males without modified posterior end .............. Hesiodeira

Blake and Hilbig, 1990

- Without facial tubercle; males with a modified posterior end carrying marginal cirri and central paired penises Lizardia Pleijel and Rouse, 2005

18(15) Parapodia biramous . . . . . . . . . . . 19

- Parapodia subbiramous ............. 20

19(18) No external genital organs; median antenna long; notosetae of a single type, slightly denticulated distally; pharynx with 10 rounded smooth papillae ............... Pleijelius $\mathrm{n}$. gen.

- Males with large ventral penises on segment 9 (chaetiger 6); median antenna short; notosetae two types, one with double rows of denticles; pharynx with 10 triangular ciliated papillae ... .... . . 'Capricornia' Pleijel and Rouse, 2000

20(18) Posterior end without anal plate; compound neurofalcigers mostly with knobby blade ..... ... Heteropodarke Hartmann-Schröder, 1962

- Posterior end provided with an expanded anal plate; most neurofalcigers with denticulated 
blades ... Microphthalmus* Mecznikow, 1865

21(14) Palpophore well developed ........22

- Palpophore reduced (palps 'simple') ........ ... . . . . . . . Parahesione Pettibone, 1956

22(21) Parapodia biramous .............23

- Parapodia subbirramous; anal cirri foliose .... . . . . . . . . . . Hesionella* Hartman, 1939

- Parapodia uniramous ................ 24

23(22) Notopodial lobes conical, short; notosetae few; neurofalcigers denticulated $\ldots \ldots \ldots \ldots$ .......... Nereimyra de Blainville, 1828

- Notopodial lobes expanded over the setal bundle; notosetae abundant; neurofalcigers smooth .... ................ Hesiolyra Blake, 1985

24(22) Pharynx with 10 distal papillae and black jaws ........ Syllidea de Quatrefages, 1866

- Pharynx without jaws ..............25

25(24) Median segments with large ventral glands on neuropodial basis; pharynx with some 20 distal papillae .... Micropodarke Okuda, 1938

- Median segments without large ventral glands; pharynx without distal papillae ........... ........... Parasyllidea Pettibone, 1961

26(1) Prostomium with three antennae . . . . . 27

- Prostomium with two antennae; parapodia uniramous; large compound ventral hooks on first chaetiger ................... . . . . . . Struwela* Hartmann-Schröder, 1959

- Prostomium without antennae; parapodia biramous; no anterior ventral hooks . ........... ................ Bonuania Pillai, 1965

27(26) Palpophore well developed; parapodia uniramous; prostomium without penis glands . . ............. Hesiocaeca Hartman, 1965

- Palpophore reduced (palps 'simple'); parapodia biramous; prostomium with penis glands in males .........Hesionides* Friedrich, 1937

\section{ACKNOWLEDGEMENTS}

Fredrik Pleijel has been especially helpful in our research on hesionids; he and Thomas Dahlgren provided useful references and advice. Kristian Fauchald, Cheryl Bight, and William Keel (USNM) helped by allowing us to study part of their collections. Partial funding for this publication was provided by Conacyt, Mexico (32529-T). Guadalupe Nieto took the SEM photographs. Luis F. Carrera helped with PAUP, and Rolando Bastida helped editing the plates. The careful reviews by Jim Blake and
Eduardo López improved the manuscript. Alexandra Rizzo noticed some inconsistencies in the key and suggested some useful changes.

\section{REFERENCES}

Dahlgren, T. and F. Pleijel. - 1995. On the generic allocation of Chrysopetalum caecum Langerhans, 1880 (Polychaeta, Chrysopetalidae). Mitt. Hamb. Zool. Mus. Inst., 92(Ergänzungsb.): 159-173.

Dahlgren, T.G., J. Lundberg, F. Pleijel, and P. Sundberg. - 2000. Morphological and molecular evidence of the phylogeny of nereidiform polychaetes (Annelida). J. Zool. Syst. Evol. Res., 38: 249-253.

Day, J.H. - 1967. Polychaeta of Southern Africa, Part 1. Errantia. London, Trustees of the British Museum (Natural History).

Fauchald, K. - 1977. The Polychaete Worms: Definitions and Keys to the Orders, Families and Genera. Nat. Hist. Mus. Los Angeles Cty., Sci. Ser., 28: 1-188.

Glasby, C.J. - 1993. Family revision and cladistic analysis of the Nereidoidea (Polychaeta: Phyllodocida). Invert. Taxon., 7: 1551-1573.

Hartman, O. - 1971. Abyssal polychaetous annelids from the Mozambique Basin off Southeast Africa, with a compendium of abyssal polychaetous annelids from World-wide areas. $J$. Fish. Res. Bd. Can., 28: 1407-1428.

Hartmann-Schröder, G. - 1977. Polychaeten aus dem Sublitoral und Bathyal vor der portugiesischen und marokkanischen Küste. Auswertung der Fahrt 8 (1967) von F.S. 'Meteor'. Meteor Forsch. Ergeb. Reihe D, 26: 65-99.

Hartmann-Schröder, G. - 1982. Die Polychaeten der Fahrt 36 (1975) von F.S. "Meteor" in das Auftriebsgebiet vor NordwestAfrika. Meteor Forsch. Ergeb. Reihe D, 35: 1-20.

Kirkegaard, J.B. - 1995. Bathyal and abyssal polychaetes (Errant species). Galathea Rep., 17: 7-56.

Maddison, D.R. and W.P. Maddison. - 2001. MacClade 4: Analysis of Phylogeny and Character Evolution, version 4.05 (Computer program and manual), Sinauer Associates, Sunderland.

Perkins, T.H. - 1985. Chrysopetalum, Bhawania and two new genera of Chrysopetalidae (Polychaeta) principally from Florida. Proc. Biol. Soc. Wash., 98: 856-915.

Petersen, M.E., T.H. Perkins and J.M. Orensanz. - (in revision). A contribution to the systematics of the lesser chrysopetalids (Polychaeta: Chrysopetalidae).

Pettibone, M.H. - 1970. Polychaeta Errantia of the Siboga-Expedition, 4. Some additional polychaetes of the Polynoidae, Hesionidae, Nereidae, Goniadidae, Eunicidae, and Onuphidae, selected as new species by the late Dr. Hermann Augener with remarks on other related species. Siboga-Exped., 24: 1-72 (199-270).

Pleijel, F. - 1998. Phylogeny and classification of Hesionidae (Polychaeta). Zool. Scr., 27: 89-163.

Pleijel, F. - 2001. Revision of Amphiduros Hartman, 1959 (Polychaeta, Hesionidae, Gyptini). Ophelia, 54: 15-27.

Pleijel, F. and T. Dahlgren. - 1998. Position and delineation of Chrysopetalidae and Hesionidae (Annelida, Polychaeta, Phyllodocida). Cladistics, 14: 129-150.

Pleijel, F. and G.W. Rouse. - 2000. A new taxon, Capricornia (Hesionidae, Polychaeta), illustrating the LITU (Least Inclusive Taxonomic Unit) concept. Zool. Scr., 29: 157-168.

Pleijel, F. and G.W. Rouse. - 2005. Reproductive biology of a new hesionid polychaete from the Great Barrier Reef. Biol. Bull., 208: 69-76.

Ruta, C. and F. Pleijel. - 2006. A new branchiate hesionid polychaete (Annelida, Hesionidae) from New Caledonia. Zoosystema, 28: 655-667.

Swofford, D.L. - 1998. PAUP*: Phylogenetic Analysis using Parsimony (and Other Methods), version 4. Sinauer Associates, Sunderland.

Watson-Russell, C. - 1991. Strepternos didymopyton Watson Russell in Bhaud and Cazaux, 1987 (Polychaeta: Chrysopetalidae) from experimental wooden panels in deep waters of the Western North Atlantic. Ophelia, Suppl. 5: 283-294. 
166 • S.I. SALAZAR-VALLEJO and J.M. ORENSANZ

Watson-Russell, C. - 2000. Family Chrysopetalidae. In: P.L. Beesley et al. (eds.), Polychaetes and allies: The southern synthesis. Fauna of Australia 4A Polychaeta, Myzostomida, Pogonophora, Echiura, Sipuncula, pp 121-125. Melbourne, CSIRO.

Westheide, W. - 2000. Mahesia ammophila, a new genus and species of interstitial hesionid (Annelida: Polychaeta) from the Indian Ocean. Proc. Biol. Soc. Wash., 113: 644-651.
Wilson, R.S. - 2000. Family Hesionidae. In: P.L. Beesley et al. (eds.), Polychaetes and allies: The southern synthesis. Fauna of Australia 4A Polychaeta, Myzostomida, Pogonophora, Echiura, Sipuncula, pp 131-133. Melbourne, CSIRO.

Received September 14, 2004. Accepted May 11, 2005. 